\title{
Üniversite Öğrencilerinin Mobil Cihazlarda Lokasyon Tabanlı Servisleri Kullanımına Yönelik Bir Araştırma: SDÜ Kılıçarslan Yerleşkesi Örneği
}

\author{
Abdullah GUNAY ${ }^{1^{*}}$, Adnan KALKAN ${ }^{2}$ \\ ${ }^{1}$ Mehmet Akif Ersoy University, Social Sciences Institute, Orcid id: 0000-0002-5006-1448 \\ ${ }^{2}$ Assoc. Prof. Dr., Mehmet Akif Ersoy University, Bucak Faculty of Business Administration, Departman of \\ Business Administration, Orcid id: 0000-0002-2270-4100
}

Geliş Tarihi/Received: 18.08.2018

Kabul Tarihi/Accepted: 06.02.2019
Doi: dx.doi.org/10.31200/makuubd.454463 Araştırma Makalesi/Research Article

\section{ÖZET}

Günümüzde mobil teknolojilerin gelişmesiyle birlikte gerek kişiler, kişisel işlemlerini gerekse işletmeler, çeşitli faaliyetlerini mobil araçlarla gerçekleştirmeye başlamışlardır. Mobil cihazlarda konum bilgilerini belirleyerek yer tespiti sağlayan konum tabanlı uygulamaların kullanımının artmasıyla beraber, bu tür uygulamalar kullanıcı tepkileri açısından önemli bir konu olmaya başlamıştır. Çalışmanın amacı, kullanıcıların akıllı telefonlarda konum tabanlı servisleri kullanım niyetini Birleştirilmiş Teknoloji Kabul ve Kullanım Modelini kullanılarak tahmin etmeye çalışmaktır. Çalışma kapsamında nicel araştırma yöntemi ile 280 üniversite öğrencisinin katılımıyla bir anket çalışması gerçekleştirilmiştir. Yapılan anket çalışmasında Janssen'in (2009) kullandığ 1 soru setinden faydalanılmıştır. Elde edilen verilerin analizi sonucunda Birleştirilmiş Teknoloji Kabul ve Kullanım Model'inin “Performans Beklentisi”, "Çaba Beklentisi", "Sosyal Etki" ve "Kolaylaştırıcı Şartlar" olmak üzere 4 boyutu ayrı ayrı ele alınarak konum tabanlı servisleri kullanım niyeti üzerinde etkili olduğu gözlemlenmektedir.

Anahtar kelimeler: Konum Tabanlı Servisler, Mobil uygulamalar, Birleştirilmiş Teknoloji Kabul ve Kullanım Modeli. 


\title{
A Research for University Students' Use of Location Based Services on Mobile Devices: SDU Kılıcarslan Campus Example
}

\begin{abstract}
Today, with the development of mobile technologies, individuals, personal operations and businesses have started to realize their various activities through mobile devices. With the use of location-based applications that provide location detection by identifying location information on mobile devices, such applications have become an important issue for user responses. The purpose of the study is to try to estimate the users' intention to use locationbased services on smartphones using the Unified Technology Acceptance and Use Model. A survey study was conducted with the participation of 280 university students using simple random sampling method. The questionnaire survey was made using Janssen's (2009) work. It is observed that the Unified Technology Acceptance and Use Model has four dimensions, "Performance Expectation", "Effort Expectation", "Social Impact" and "Facilitating Conditions".
\end{abstract}

Keywords: Location Based Services, Mobile Applications, Unified Theory Of Acceptance And Use Of Technology.

\section{GIRİŞ}

Günümüzde, bilişim teknolojilerin yaygınlaşmasıyla birlikte akıllı telefon kullanımı hızla artmaktadır. Türkiye İstatistik Kurumu'nun yaptı̆̆ı çalışmaya göre; hanelerde cep telefonu/ak1llı telefon bulunma oranının 2004 y1lında \%53,7 iken 2016 y1lında \%96,9'a yükseldiği görülmüştür (http://www.tuik.gov.tr). Aynı zamanda Pew Research Center'in 2016 yılında yaptığı araştırmaya göre akıllı telefona sahip olmanın yüksek olduğu ülkeler arasında Türkiye \% 59 ile dünyada akıllı 12. sırada yer almaktadır (pewresearch.org, 2016).

Mobil teknolojinin kişilerin hayatlarında çok önemli bir yere sahip olması ile birlikte gerek kişiler, kişisel işlemlerini gerekse işletmeler, çeşitli faaliyetlerini mobil araçlarla gerçekleştirmeye başlamışlardır (Wang vd., 2013:11). Tüketiciler mobil cihazlarla, mesajlaşmadan, televizyon izlemeye, biletler satın almaya, rezervasyon yapmaya, bankacılık işlemleri gerçekleştirmeye, gazete okumaya, herhangi bir ürünü sipariş vermeye kadar tüm işlemleri çok hızlı ve pratik biçimde gerçekleşmektedir. Bu durum, tüketicilerin hayatlarını kolaylaştırmaktadır. Son yıllarda akıllı telefonlara eklenen konum tabanlı özelliği ile kullanıcılar kendi konum bilgilerini kullanmaktadır. Daha önceden akıllı telefonlarda konuma 
dayalı servisler sadece basit yer izleme servisleri ile sınırlıydı. Ancak gelişen akıllı telefonlar, güçlü işletim sistemleri ve çeşitli uygulamalarıyla konuma dayalı servisleri tamamen değiştirdiler. (Yun vd., 2013:215).

Mobil cihazların konum bilgilerini belirleyerek yer tespiti sağlayan lokasyon tabanlı uygulamaların kullanımının artmasıyla beraber, bu tür uygulamalar kullanıcı tepkileri açısından önemli bir konu olmaya başlamıştır (Daştan, 2015: 34). Günümüzde mobil uygulamalarda lokasyon tabanlı servisler birçok alanda kullanılmaktadır (Kushwaha, 2011: $14)$.

Bu bağlamda araştırmanın amacı, konum tabanlı servislerin kullanımını inceleyerek; bu kullanımın altındaki nedenleri ve bu nedenlerin önemini belirlemek ve Birleştirilmiş Teknoloji Kabul ve Kullanım Modelini kullanıcıların konum tabanlı servisleri kullanım niyetini belirlemektir.

\section{LITERATÜR ÇALIŞMASI}

Literatürde bulunan çalışmalar incelendiği zaman, çoğunlukla çalışmaların öğrenciler üzerinde yapıldığı görülmektedir. Ayrıca yapılan çalışmaların çoğunda kullanıcıların lokasyon tabanlı servisleri kullanımını gizlilik açısından incelemiştir.

Kaya ve arkadaşları yaptıkları çalışmada lokasyon tabanlı mobil kampüs uygulaması tasarlayarak öğrenciler tarafından kullana bilirliğini değerlendirmişlerdir. (Kaya vd.,2014). Ertuğrul ve Önal (2014) çalışmalarında android işletim sisteminde konum tabanlı bir hatırlatma uygulaması geliştirerek sosyal ă̆ uygulama programlama arayüzlerini kullanarak çeşitli yer etiketleme seçenekleriyle zenginleştirilmiş, konuma bağlı bir hatırlatma uygulaması önermektedir. Şaşmaz (2017) çalışmasında Swarm uygulamasını örnek alarak üniversite öğrencilerinin yeme- içme deneyimlerinin konum tabanlı mobil uygulamalar üzerinden paylaşım motivasyonlarını incelemiştir. Daştan (2015), genç kullanıcıları konu alarak konum tabanlı sosyal ă̆ uygulamalarını kullanma Davranışlarını araştırmıştır. Şahan (2013) ise çalışmasında, konum tabanlı mobil sosyal ağ kullanıcılarının özelliklerini, uygulamayı kullanma pratiklerini ve selektif benlik sunumu eğilimlerini ele almıştır. Yun ve arkadaşları çalışmalarında konum tabanlı mobil uygulamaların kullanımının gizlilik konusunda önem arz edip etmediğini anlamaya çalışmışlardır (Yun vd., 2013). Vicente vd., yaptıkları çalışmada konum tabanlı sosyal ağlarda gizlilik tehditleri ele alınarak bu tehditlere karşı gizlilik koruma teknolojilerinin durumunu analiz etmişlerdir (Vicente vd., 2011). Kushwaha ve Kushwaha 
çalışmalarında Android işletim sisteminde konum tabanlı servislerin kullanımından bahsetmişlerdir (Kushwaha ve Kushwaha, 2011). Chin yaptı̆̆ çalışmada, konum tabanlı hizmetlerin kritik başarı faktörlerini incelemiştir (Chin,2012 ). Barkhuus ve Dey çalışmalarında konuma dayalı hizmetlerle ilgili olarak kişilerin mahremiyet konusundaki kaygılarını inceleyen bir vaka çalışması sunup iki tip hizmetin (konum takibi ve konum bilgisi ) insanlara sağladığı faydaları karşılaştırılmıştır (Barkhuus ve Dey, 2003). Brennan (2015) ise çalışmasında, konum tabanlı sosyal uygulamaların nasıl kullanıldığını incelemiştir. Öz yaptı̆̆ı çalışmada mekân bağlılığını Foursquare uygulamasıyla inceleyerek bağlılık derecesi ile yer bildirim sıklığının ilişkisini araştırmıştır (Öz, 2014).

\section{KURAMSAL ÇERÇEVE}

\subsection{Akıllı Telefon Kavramı}

Daha gelişmiş bilgi işlem kabiliyetlerine sahip ve normal cep telefonlarından daha fazla bağlantıya sahip cep telefonları, 90'lı yılların sonlarında tüketici pazarına girmiştir. Ancak 2007'de Apple'ın iPhone'u piyasaya sürülürken genel olarak popülerlik kazanmıştır. Android işletim sistemiyle çalışan ilk akıllı telefon ise 2008'in sonlarında pazara sunulmuştur. Akıllı telefon endüstrisi o zamandan beri pazar boyutunda olduğu kadar modellerde ve tedarikçilerde de giderek gelişip ve büyümektedir. 2018 yılına gelindiğinde, dünya nüfusunun üçte birinden fazlasının akıllı telefona sahip olması beklenmektedir. $\mathrm{Bu}$ da dünya genelinde toplamda yaklaşık 2.53 milyar akıllı telefon kullanıcısı olması tahmin edilmektedir (Statista.com).

Litchfield'in 2010'da "açık bir işletim sistemi çalıştıran ve kalıcı olarak İnternet'e bağlı" bir telefon olarak tanımladığı akıllı telefonlar (Litchfield, 2010), günümüzde kamera, veri depolama, GPS, dokunmatik ekran ve birçok özelliği barındırmaktadır. Akıllı telefonlar, tıpkı kişisel bilgisayarlar gibi, barındırdıkları işletim sistemleri sayesinde uygulama ya da eklentilerin çalışmasına imkân sunmaktadır. Kullanıcı tarafından özelleştirilen her akıllı telefon, kullanıcının ihtiyaçlarına göre farklı arayüzü ve uygulamaları içermektedir.

\subsection{Mobil Uygulama Kavramı}

Akıllı telefon kullanımın gün geçtikçe artması mobil uygulama kavramını da popüler hale getirmiştir. İlk başlarda mobil uygulamalar sınırlı özelliklere sahip cep telefonlarda yer alan, alarm, hesap makinesi vb. basit uygulamalardı. O zamanlar insanlar sadece çağrı mesajı almak, basit hesaplamalar yapmak vb. işlemler için mobil uygulamaları kullanmışlardır (Islam 
vd, 2010). Günümüzde mobil uygulamalar her mobil işletim sistemi için ayrı oluşturulup birçok alanda kullanıcıların ihtiyaçlarını karşılamak amacıyla uygulama marketlerinde veya diğer dijital platformlarda tüketicilerin hizmetine sunulmaktadır. En popüler uygulama mağazaları; Apple'ın “App Store”, Android işletim sisteminin "Google Play”, Windows işletim sisteminin "Windows Phone Store” ve BlackBerry OS 'in “ BlackBerry App World' mağazasıdır. Dünyanın önde gelen istatistik şirketlerinden Statista'nın araştırmasına göre Mart 2017 itibarıyla, dünyanın önde gelen iki uygulama mağazası olan Google Play Store'da 2,8 milyon mevcut uygulama ve Apple'ın App Store'da 2,2 milyon uygulama yer almaktadır (Statisca.com, 2017).

En popüler uygulamalar arasında, oyunlar, sosyal ağlar, haritalar, haberler, hava durumu yer almaktadır. Bunların hepsi, iletişim arabirimleri (Wi-Fi, GSM / EDGE, WCDMA / UMTS / HSPA ve Bluetooth), ses ve video işlemcileri, kamera, sensörler veya GPS gibi cihazların teknik özelliklerinden en az birisini kullanmaktadır.

\subsection{Lokasyon Tabanlı Servisler}

Lokasyon Tabanlı Servisler (LTS), ilk olmasa da 1970'lerin başında ABD Telekom operatörleri ve ABD Federal İletişim Komisyonu ile birlikte geliştirilen E911 sisteminde etkin bir şekilde kullanılmıştır. Bu telefon sistemleri Amerika Birleşik Devletleri'nde bazı eyaletlerde yapılan acil durum çağrılarının uygun acil servis çağrı odasına yönlendirilmesine izin verilmiştir (Ayres ve Mehmood, 2010). Düşük düzeyli lokasyon verilerine sahip bu hizmetler daha sonra, ek yönetmeliklere ve cep telefonu gibi yeni teknolojilere uyacak şekilde geliştirilmiştir. Akıllı telefonlardan önce daha az işlevli, daha önce özellikli telefonlar olarak bilinen cep telefonlarında, Lokasyon Tabanlı Servisler basit yer-izleme servisleri ile sınırlıydı. Ancak akıllı telefonlar, güçlü işletim sistemleri ve çeşitli uygulamalarıyla Konum Tabanlı Servisleri tamamen değiştirdiler (Yun vd, 2013). Çok çeşitli iş modelleri içeren LTS uygulamaları ortaya çıkmış ve LTS ile sosyal paylaşım hizmetleri birleştirilmiştir. Ayrıca, konuma dayalı reklamlar ve mobil ticaretin gelişmiş bir versiyonu olan konuma dayalı ticaret (L-Ticaret) ortaya çıkmıştır.

Lokasyon Tabanlı Servisler, kullanıcıların yer ve tercihlerine göre içerikle ilgili bilgileri sunar (Zhou, 2012). Bu servisler mobil uygulamalar tarafindan belirli aralıklarla otomatik olarak tetiklendiği gibi kullanıcılar tarafından da tetiklenebilmektedir 
Gunay, A. \& Kalkan, A.

\section{ARAŞTIRMANIN METODOLOJISİ VE HİPOTEZLER}

Kullanıcıların mobil uygulamalarda lokasyon tabanlı servislerin kullanımını inceleyip, bireysel bulguları, kullanıcı niyetini etkileyen faktörler üzerinde analiz etmek için bir çerçeveye ihtiyaç duyulmaktadır. Bu bağlamda Teknoloji Kabul ve Kullanım Birleştirilmiş Modelinden (TKKBM) yararlanarak çalışmaya fayda sağlaması planlanmıştır.

Şekil 1'de görüldüğü gibi Venkatesh ve arkadaşları tarafından geliştirilen Teknoloji Kabul ve Kullanım Birleştirilmiş Modeli (TKKBM) (Unified Theory of Acceptance and Use of Technology- UTAUT) 8 farklı modelin birleşiminden meydana gelmiştir. Bunlar, Teknoloji Kabul Modeli, Yenilik Yayılım Teorisi, Motivasyonel Model, Gerekçeli Eylem Teorisi, Planlı Davranış Teorisi, Teknoloji Kabul ve Planlı Davranış Teorisi birleştirilmiş modeli, PC Kullanım Modeli ve Sosyal Bilişsel Teoridir (Zhou, 2012). Teknoloji Kabul ve Kullanım Birleştirilmiş Modeli (UTAUT), "Performans Beklentisi”, "Çaba Beklentisi”, “Sosyal Etki” ve "Kolaylaştırıcı Koşullar" olmak üzere dört ana konudan oluşmaktadır. Bu dört temel kavram bağımlı değişkenleri, davranışları ve kullanımını etkileyen bağımsız değişkenlerdir. Cinsiyet, yaş, deneyim ve gönüllü sistem kullanımı dolaylı olarak dört temel kavramı etkilemektedir. Davranışsal niyet, teknoloji kullanımının kritik öngörücüsü olarak görülmektedir.

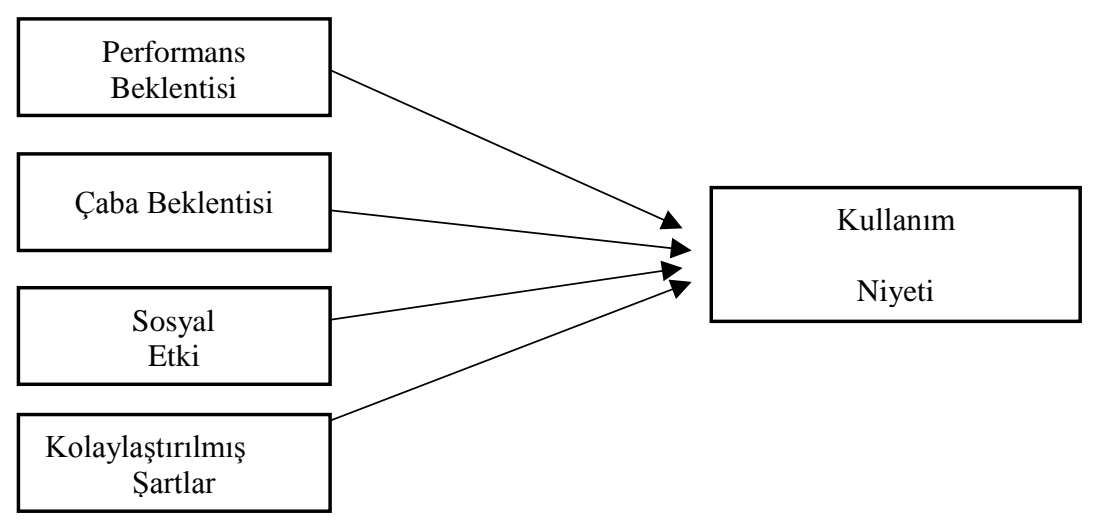

Şekil 1: Araştırma modeli

\subsection{Performans Beklentisi}

Performans beklentisi, belirli bir teknolojinin kullanımının görev performansını artırmak için yararlı olacağının derecesi olarak tanımlanır. Performans beklentisi, farklı modellerden elde edilen beş yapıdan esinlenmektedir:1. Algılanan kullanışlılık, TAM/TAM2 ve Birleştirilmiş TAM ve TPB (C-TAMTPB)'den, 2. Dış motivasyon, Motivasyonel Model'den (Motivational Model-MM), 3. İş uyumu beklentisi, PC Kullanım Modeli'nden 
(Model of PC UtilizationMPCU), 4. Göreceli avantaj, Yeniliklerin Yayılımı Teorisi'nden (Innovation Diffusion Theory-IDT) ve 5. Çıktı beklentileri, Sosyal KavramTeorisi (Social Cognitive Theory-SCT)'nden elde edilmiştir (Venkatesh vd., 2003: 447). Konum Tabanlı Servisler bağlamında performans beklentisi, konum tabanlı servislerin amaçlanan sonuçları uygun bir şekilde sunma yeteneği kavramını tamımlar; Başka bir deyişle, konum tabanlı servisleri kullanmanın enstrümantal değeridir (Yun vd, 2013).

H1: Performans beklentisi, kullanım niyeti üzerinde olumlu bir etkiye sahiptir.

\section{2. Çaba Beklentisi}

Çaba Beklentisi, Sistem kullanımı ile ilgili zorluk derecesi olarak tanımlanır. Mevcut modellerden elde edilen üç yapı; algılanan kullanım kolaylığı (TAM/TAM2), karmaşıklık (MPCU) ve kullanım kolaylığı (IDT), çaba beklentisi kavramı çerçevesinde ele alınmaktadır.

Çaba beklentisi, konum Tabanlı servislerin kullanımının zorluğunu yansıtmaktadır. Küçük ekranlar ve uygun olmayan girdi gibi mobil terminallerin kısıtlamaları nedeniyle, kullanıcıların mobil uygulamaları çalıştırması nispeten zordur (Lee ve Benbasat, 2004). Buna ek olarak, kullanıcılar ortaya çıkan bir hizmeti temsil eden konum tabanlı servislere aşina olmayabilir. Bu aynı zamanda konum tabanlı servisleri kullanma zorluklarını da arttırabilir (Zhou vd,2012).

H2: Çaba beklentisi, kullanım niyeti üzerinde olumlu bir etkiye sahiptir.

\subsection{Sosyal Etki}

Sosyal Etki, birey için yeni bir sistemi diğer kişilerden etkilenerek kullanması gerektiği algısı olarak tanımlanmaktadır ( Venkatesh vd. ,2003). Aynı zamanda sosyal etki bireyin inandıklarını ve davranışını bir kişi veya grubun gerçek veya hayali, niyetli veya niyetsiz baskısının etkisiyle değiştirmesidir. Sosyal etki teorisine göre, kullanıcılar diğer önemli bireylerin görüşlerine uyma eğilimindedir (Bagozzi ve Lee, 2001). Dolayısıyla Lokasyon Tabanlı Servislerin bireyin çevresinde kullanılması bireyin bu servisleri kullanma niyetini etkilemektedir.

H3: Sosyal etki, kullanım niyeti üzerinde olumlu bir etkiye sahiptir. 
Gunay, A. \& Kalkan, A.

\subsection{Kolaylaştırılmış Şartlar}

Kolaylaştırılmış şartlar, bireysel kullanıcılardan farklı olarak, sistemin kullanımını desteklemek için organizasyonel ve teknik altyapıya sahip olduğuna inanmaktadır. $\mathrm{Bu}$ belirleyicinin yapıları 'algılanan davranış kontrolü', 'kolaylaştırıcı koşullar' ve 'uyumluluk' şeklindedir. Bu yapıların her biri, kullanım engellerini kaldırmak için tasarlanmış teknolojik ve / veya organizasyonel çevreyi göz önünde bulundurarak işlev görür (Venkatesh vd, 2003).

H4: Kolaylaştırıcı şartlar, kullanım niyeti üzerinde olumlu bir etkiye sahiptir.

\section{ARAŞTIRMANIN YÖNTEMI}

\subsection{Araştırmanın Evreni ve Örneklemi}

Araştırma evreni, çalışmanın yapıldığı süre içerisinde Süleyman Demirel Üniversitesi Kılıçaslan Yerleşkesi'nde eğitim gören lisans ve önlisans öğrencilerinden meydana gelmektedir. Kılıçarslan Yerleşkesi'nde yer alan yüksekokul ve meslek yüksekokullarında toplam 3945 öğrenci bulunmaktadır (obs.sdu.edu.tr, 2017). Araştırmaya basit tesadüfi örnekleme yöntemi ile 3945 öğrenci arasından seçilen 280 öğrenci katılmıştır.

\section{2. Ölçeklerin Oluşturulması ve Verilerin Toplanması}

Akıllı telefonlarda konum tabanlı servislerin kullanımını belirlemek için kullanılan UTAUT modeline ek olarak mobil uygulamaların kullanımı konusunda kullanıcıların görüşlerine ihtiyaç duyulmaktadır (Janssen, 2009). Araştırmada kullanılan ölçekte Janssen'in "Mobile Location-Based Services: Barriers to and Factors Influencing the Adoption of Location Sharing on Mobile Devices” adlı çalışmasından yararlanılmıştır.

Hazırlanan anket formu 3 bölümden oluşmaktadır. İlk bölümde katılımcıların demografik bilgilerine ait sorular, ikinci bölümde mobil uygulama kullanımına ait sorular, üçüncü bölümde ise kullanılan modellere göre ölçek ifadeleri yer almaktadır. İfadeler UTAUT'un ölçek maddeleri baz alınarak, 5'li Likert ölçeğinde hazırlanmıştır (1= Kesinlikle Katılmiyorum, ..., 5=Kesinlikle Katıliyorum). 
Tablo 1. Ankette kullanılan ifadeler

\begin{tabular}{|c|c|}
\hline \multirow{3}{*}{$\begin{array}{l}\text { Performans } \\
\text { Beklentisi }\end{array}$} & $\begin{array}{l}\text { Konum bilgilerimi sosyal ağımdaki kişilerle paylaşmanın yararlı olduğuna } \\
\text { inanıyorum. }\end{array}$ \\
\hline & $\begin{array}{l}\text { Arkadaşlarımın konum bilgilerini bildiğim zaman onlarla daha kolay bir araya } \\
\text { gelebilirim. }\end{array}$ \\
\hline & Konum Servislerini kullanırsam, arkadaşlarımla bağlantılarımı iyileştireceğim. \\
\hline \multirow{4}{*}{ Çaba Beklentisi } & Konumu paylaşma kavramının açık ve anlaşılır olduğuna inanıyorum. \\
\hline & $\begin{array}{l}\text { İnsanların benim konum bilgilerime erişiminin kontrolünün kolay olduğuna } \\
\text { inanıyorum. }\end{array}$ \\
\hline & $\begin{array}{l}\text { Konum bilgilerimi bir mobil sosyal ağda paylaşmanın kolay olduğunu } \\
\text { düşünüyorum. }\end{array}$ \\
\hline & $\begin{array}{l}\text { Cep telefonumda bir yer paylaşım servisi kurmanın öğrenilmesinin kolay olduğuna } \\
\text { inanıyorum. }\end{array}$ \\
\hline \multirow{3}{*}{ Sosyal Etki } & $\begin{array}{l}\text { Ailem ve arkadaşlarım konum bilgilerinin paylaşmanın faydalı olduğunu } \\
\text { düşünmektedir }\end{array}$ \\
\hline & $\begin{array}{l}\text { İnsanların konum bilgilerini paylaşmanın avantajlı olduğu düşüncesi benim için } \\
\text { önemlidir. }\end{array}$ \\
\hline & $\begin{array}{l}\text { Arkadaşlarımın çoğu konum bilgilerini paylaşırsa ben de onlar gibi konum } \\
\text { bilgilerimi paylaşırım. }\end{array}$ \\
\hline \multirow{2}{*}{$\begin{array}{l}\text { Kolaylaştırıcı } \\
\text { Şartlar }\end{array}$} & Konum paylaşımı hakkında kolayca bilgi bulabileceğimi düşünüyorum. \\
\hline & $\begin{array}{l}\text { Konum paylaşımının kolay ve hızlı yapılmasını bir teknik altyapının olduğuna } \\
\text { inanıyorum. }\end{array}$ \\
\hline \multirow{5}{*}{ Kullanım Niyeti } & Şu anda konum bilgilerimi paylaşıyorum ve bunu yapmaya devam edeceğim. \\
\hline & Şu anda bir mobil sosyal ağ üzerinde konumumu paylaşıyorum. \\
\hline & $\begin{array}{l}\text { Ben gelecekte bir cep telefonu üzerinden konum bilgilerimi paylaşacağımı tahmin } \\
\text { ediyorum. }\end{array}$ \\
\hline & $\begin{array}{l}\text { Ben gelecekte bir mobil sosyal ağ içinde konumumu paylaşacağımı tahmin } \\
\text { ediyorum. }\end{array}$ \\
\hline & Bir sonraki cep telefonu seçtiğimde, konum özelliği olan bir telefon tercih ederim. \\
\hline
\end{tabular}

\subsection{Geçerlilik ve Güvenilirlik}

Araştırmada ölçeklerin güvenilirliklerini test etmek için Cronbach’s Alpha yöntemine başvurulmuştur. Cronbach's Alpha değeri 0 ile 1 arasında bir değer almaktadır. Ayrıca kullanılan ölçeğin güvenilir olması için alfa katsayısının 0.70 ve üzerinde olması gerekmektedir (Taber, 2017). Araştırma modelinde yer alan boyutların güvenilirliği ayrı ayrı 
Gunay, A. \& Kalkan, A.

incelendiğinde elde edilen Cronbach's Alpha değerleri Tablo 2'de yer almaktadır. Performans beklentisi, çaba beklentisi, sosyal etki ve kullanım niyeti boyutu 0.70 'in üzerinde olmakla birlikte kolaylaştırıcı şartlar boyutu 0.70 ' e yakın bir değerdedir.

Tablo 2. Cronbach's alpha testi

\begin{tabular}{|l|c|c|}
\hline \multicolumn{1}{|c|}{ Boyutlar } & Madde Sayısı & $\begin{array}{c}\text { Cronbach's } \\
\text { Alpha Değeri }\end{array}$ \\
\hline Performans Beklentisi & 3 &, 776 \\
\hline Çaba Beklentisi & 4 &, 705 \\
\hline Sosyal Etki & 3 &, 778 \\
\hline Kolaylaştırıcı Şartlar & 2 &, 644 \\
\hline Kullanım Niyeti Toplam & 5 &, 880 \\
\hline \multicolumn{1}{r|}{ Tom } \\
\hline
\end{tabular}

Ayrıca araştırmada verilerin normal dağılımını görebilmek için One Sample Kolmogorov Smirnov Testi yapılmıştır. Normal dağılım testi sonucunda verilerin normal dağıldığı hipotezi reddedilmiştir $(\mathrm{p}<0.05)$. Ancak verilerin çarpıklık ve basıklık değerlerine bakıldığında bu değerlerin -2 ve +2 aralığında kaldığı görülmüş ve verilerin normal dağıldığı kabul edilmiştir (George ve Mallery, 2016).

\subsection{Araştırmanın Analizleri ve Bulguları}

\subsubsection{Demografik bulgular}

Yapılan araştırmaya 280 kişi katılmıştır. Katılanların demografik bilgileri Tablo 3'te verilmiştir. Katılımcıların \%60,4'ünü kadın \% 39,6'sını erkek öğrenciler oluşturmaktadır. Aynı zamanda katılan öğrencilerin \% 30,4'ünü 4. Sınıf, \% 28,6’sı 3. Sınıf, \% 25'ini 2. Sınıf, $\% 16,1$ 'ini 1. Sınıf öğrencileri oluşturmaktadır.

Tablo 3. Katılımciların demografik bilgileri

\begin{tabular}{|c|c|c|}
\hline Cinsiyet & Frekans & Yüzde \\
\hline Kadın & 169 & 60,4 \\
\hline Erkek & 111 & 39,6 \\
\hline Sınıf & Frekans & Yüzde \\
\hline 1 & 45 & 16,1 \\
\hline 2 & 70 & 25 \\
\hline 3 & 80 & 28,6 \\
\hline 4 & 85 & 30,4 \\
\hline
\end{tabular}




\subsubsection{Korelasyon analizi}

Korelasyon analizinde; bağımlı ve bağımsız değişkenler arasındaki ilişki ölçülmeye çalışılmıştır. Tablo 4’te de görüldüğü üzere $\mathrm{PB}, \mathrm{CB}$, SE ve KS ile KN arasında \%99 güvenilirlikte bir ilişkinin olduğu söylenebilir. Başka bir ifade ile Kullanım niyeti ile Performans beklentisi arasında yüksek, kullanım niyeti ile çaba beklentisi ve kullanım niyeti ile arasında orta, kullanım niyeti ile arasında ve kolaylaştırıcı şartlar arasında zayıf bir ilişkinin olduğu görülmektedir.

Tablo 4. Korelasyon analizi sonuçları

\begin{tabular}{|c|c|c|c|c|c|}
\hline & PB_ORT & CB_ORT & SE_ORT & KS_ORT & KN_ORT \\
\hline PB_ORT & 1 & & & & \\
\hline CB_ORT &, $522^{* *}$ & 1 & & & \\
\hline SE_ORT &, $613^{* * *}$ &, $422^{* *}$ & 1 & & \\
\hline KS_ORT &, $296^{* *}$ &, $567^{* *}$ &, $318^{* *}$ & 1 & \\
\hline KN_ORT &, $707^{* *}$ &, $619^{* *}$ &, $666^{* *}$ &, $476^{* *}$ & 1 \\
\hline
\end{tabular}

(** 0.01 düzeyinde anlamlıdır)

\subsubsection{Regresyon analizi}

Regresyon analizinde bağımlı değişken üzerindeki bağımsız değişkenlerin etkisini ölçülmeye çalışılmıştır. Regresyon Analizi, değişkenlerin detaylı analizini mümkün kılar ve değişkenler arasındaki korelasyonlara dayanmaktadır (Jolliffe, 1986:167). Faktör Analizi ve Cronbach'ın $\alpha$ analizi sonrasında oluşturulan yapı, Performans Beklentisi, Çaba Beklentisi, Sosyal Etki, Kolaylaştırıcı Şartlar ve bağımlı değişken olarak Kullanım Niyetinden oluşmaktadır.

Modelin p-değeri modelin önemini açıklamak için bir ölçüttür. P-değeri 0,05 'den düşük olduğunda model genel olarak anlamlı kabul edilir. Bu, bağımsız değişkenler tarafından bağımlı değişkende açıklanan varyansa göre düzeltilmiş R2'nin gerçek olma şansının \%95 olması anlamına gelir. 0,05 ile 0,10 arasında bir p-değeri zayıf olarak kabul edilir ve 0.10'dan yüksek bir p-değeri istatistiksel olarak anlamlı olmadığı düşünülür (MacCallum, vd., 1996:134). Bu çalışmada kullanılan regresyon analizi Tablo 5'de gösterilmektedir. 
Gunay, A. \& Kalkan, A.

Tablo 5. Performans beklentisinin (PB), çaba beklentisinin (CB), sosyal etkinin (SE) ve kolaylaştırıcı şartların (KS) kullanım niyeti $(\mathrm{KN})$ etkisine yönelik regresyon analizinin model özeti

\begin{tabular}{|c|c|c|c|c|}
\hline Model & $\mathbf{R}$ & $\mathbf{R}^{2}$ & $\begin{array}{c}\text { Düzeltişmiş } \\
\mathbf{R}^{2}\end{array}$ & $\begin{array}{c}\text { Hesaplanan } \\
\text { Standart Hata }\end{array}$ \\
\hline 1 &, $815^{\text {a }}$ &, 664 &, 660 &, 40849 \\
\hline \multicolumn{4}{|l}{ a. Tahmini Değişken: (Sabit), KS_ORT, PB_ORT, SE_ORT, } \\
CB_ORT
\end{tabular}

Hesaplanan $\mathrm{R}^{2}=0,664$ olduğunu ortaya koymaktadır. Bu, modelin, yüksek kabul edilen bağımlı değişken Kullanma Niyeti varyansının \%66,4'ünü açıkladığı anlamına gelmektedir. Yüksek bir $\mathrm{R}^{2}$ değeri, Modelin Kullanım Niyetini açıklama konusundaki gerçekliğinin güçlü olduğu anlamına gelmektedir.

Tablo 6. Performans beklentisinin (PB), çaba beklentisinin (CB), sosyal etkinin (SE) ve kolaylaştırıcı şartların (KS) kullanım niyeti $(\mathrm{KN})$ etkisine yönelik regresyon analizinin

ANOVA testi

\begin{tabular}{|l|l|c|c|c|c|c|}
\hline \multicolumn{2}{|c|}{ Model } & $\begin{array}{c}\text { Kareler } \\
\text { Toplamı }\end{array}$ & $\begin{array}{c}\text { Serbestlik } \\
\text { derecesi }\end{array}$ & $\begin{array}{c}\text { Ortalamaların } \\
\text { Karesi }\end{array}$ & F & Anlamlılık \\
\hline \multirow{2}{*}{1} & Regresyon & 90,856 & 4 & 22,714 & 136,125 &, $000^{\mathrm{b}}$ \\
\cline { 2 - 7 } & Artık & 45,887 & 275 &, 167 & & \\
\cline { 2 - 7 } & Total & 136,743 & 279 & & & \\
\hline
\end{tabular}

Tablo 6' daki ANOVA tablosu incelendiğinde $F$ değeri 136,125 ve $p$ değeri 0,00 olduğundan, oluşturulan regresyon modeli genelde istatistiksel olarak anlamlıdır. Yani kullanım niyetini, performans beklentisi, çaba beklentisi, sosyal etki ve kolaylaştırılmış şartlar değişkenlerinden en az biri ile tahmin etmek istatistiksel olarak mümkündür. 
Tablo 7. Performans beklentisinin (PB), çaba beklentisinin (CB), sosyal etkinin (SE) ve kolaylaştırıcı şartların (KS) kullanım niyeti (KN) etkisine yönelik regresyon analizinin katsayıları

\begin{tabular}{|c|c|c|c|c|c|c|}
\hline & \multirow[t]{2}{*}{ Model } & \multicolumn{2}{|c|}{$\begin{array}{c}\text { Standardize } \\
\text { Edilmemis Katsayı }\end{array}$} & \multirow{2}{*}{$\begin{array}{c}\text { Standardize } \\
\text { Edilmiş Katsayı }\end{array}$} & \multirow[t]{2}{*}{ t } & \multirow[t]{2}{*}{ Anlamlılık } \\
\hline & & $\mathbf{B}$ & Standart Hata & & & \\
\hline \multirow{5}{*}{1} & (Sabit) & ,763 & ,103 & & 7,401 & ,000 \\
\hline & PB_ORT & ,251 & ,033 & ,362 & 7,603 & ,000 \\
\hline & CB_ORT & ,186 & ,041 & ,216 & 4,541 & ,000 \\
\hline & SE_ORT & ,225 & ,033 & ,305 & 6,764 & ,000 \\
\hline & \begin{tabular}{|l|} 
KS_ORT \\
\end{tabular} & ,117 & ,033 & ,150 & 3,501 & ,001 \\
\hline
\end{tabular}

Performans beklentisinin, çaba beklentisinin, sosyal etkinin ve kolaylaştırıcı şartların kullanım niyeti etkisine yönelik regresyon analizinin katsayıları incelendiğinde aşağıdaki bulgulara ulaşılmıştır;

$\mathrm{P}_{\mathrm{PB}}: \quad 0,000<0,05$ olduğundan Performans Beklentisinin, Kullanım Niyeti üzerine etkisini gösteren Regresyon modeli; $\mathrm{Y}_{\mathrm{PB}}=0,763+0,251(\mathrm{~PB})$ şeklinde $\left(\mathrm{H}_{1}\right.$ kabul) yazılabilir.

$\mathrm{P}_{\mathrm{CB}}: 0,000<0,05$ olduğundan Çaba Beklentisinin, Kullanım Niyeti üzerine etkisini gösteren Regresyon modeli; $\mathrm{Y}_{\mathrm{CB}}=0,763+0,186(\mathrm{CB})$ şeklinde $\left(\mathrm{H}_{2}\right.$ kabul $)$ yazılabilir.

$\mathrm{P}_{\mathrm{SE}}: 0,000<0,05$ olduğundan Sosyal Etkinin, Kullanım Niyeti üzerine etkisini gösteren Regresyon modeli; $\mathrm{Y}_{\mathrm{SE}}=0,763+0,225(\mathrm{CB})$ şeklinde $\left(\mathrm{H}_{3} \mathrm{kabul}\right)$ yazılabilir.

$\mathrm{P}_{\mathrm{KS}}: 0,000<0,05$ olduğundan Kolaylaştırıcı Şartların, Kullanım Niyeti üzerine etkisini gösteren Regresyon modeli; $\mathrm{Y}_{\mathrm{KS}}=0,763+0,117(\mathrm{CB})$ şeklinde $\left(\mathrm{H}_{4}\right.$ kabul) yazılabilir.

\section{SONUÇ}

Son yıllarda bilişim teknolojileri akıl almaz bir hızda gelişim göstermekte ve hayatımızın her alanında kullanılabilir hale gelmiştir. Bu gelişmeler mobil cihazlarda çeşitli özelliklerin artmasına da imkân sağlamaktadır. Bu özelliklerden bir tanesi de konum tabanlı servislerdir. Konum tabanlı servislerin kullanıcılar tarafından hangi amaçla kullandığı, tutum ve davranışları, Birleştirilmiş Teknoloji Kabul ve Kullanım Modeli kullanılarak tahmin edilmeye çalışılmıştır. 280 üniversite öğrencisinin katılımıyla gerçekleştirilen anket çalışmasıyla elde edilen verilerin analizi sonucunda Birleştirilmiş Teknoloji Kabul ve 
Gunay, A. \& Kalkan, A.

Kullanım Modelinin konum tabanlı servisleri kullanım niyeti üzerinde etkili olduğu görülmüştür.

Elde edilen bulgulara göre; Performans Beklentisinin, konum tabanlı servislerin kullanım niyeti üzerine etkisi gözlemlenmektedir. Bu durum akıllı telefon kullanıcılarının görev performansını artırmak için yararlı olacağının derecesini göstermektedir. Çaba Beklentisinin, konum tabanlı servislerin kullanım niyeti üzerinde anlamlı bir etkiye sahiptir. $\mathrm{Bu}$ etki kullanıcıların konum tabanlı servislerin kullanımının zorluğunu yansıtmaktadır. Sosyal Etkinin, konum tabanlı servislerin kullanım niyeti üzerinde etkisi vardır. Bu durum ise konum tabanlı servisleri kullananların etrafındaki kişilerden etkilendiğini açıklamaktadır. Kolaylaştırıcı Şartlar, konum tabanlı servislerin kullanım niyeti üzerinde etkilidir. Bu da konum tabanlı servislerin kullanımın kullanıcılar tarafından gerekli bilgi ve teknik altyapıya sahip olup olmadığg ile açıklanabilmektedir.

\section{REFERENCES / KAYNAKLAR}

Ayres, G. \& Mehmood, R. (2010). LocPriS: A security and privacy preserving location based services development framework. Knowledge-Based And Intelligent Information And Engineering Systems, 566-575.

Bagozzi, R. P., \& Lee, K. H. (2002). Multiple routes for social influence: the role of compliance, internalization, and social 1dentity. Social Psychology Quarterly, 226-247.

Barkhuus, L. \& Dey, A. K. (2003). Location-based services for mobile telephony: a study of users' privacy concerns. Interact, 702-712.

Brennan, S. (2015). How location-based social network applications are being used. Jyväskylän Yliopisto Tietojenkäsittelytieteiden Laitos.

Chin, N. J. P. (2012). Critical success factors of location-based services. Dissertations, Theses, and Student Research from the College of Business.

Daştan, İ. (2015). Konum tabanlı sosyal ağ uygulamalarını kullanma davranışları: genç kullanıcılar üzerinde bir araştırma. Sakarya İktisat Dergisi, 4(4),76-95.

Ertuğrul, A. M. \& Önal, I. (2014). Çeşitli konum etiketleme opsiyonlarıyla zenginleştirilmiş yeni bir konum bazlı hatırlatma uygulaması. 8. Ulusal Yazılım Mühendisliği Sempozyumu, 802-813.

George, D. \& Mallery, P. (2016), IBM SPSS Statistics 23 Step By Step: A Simple Guide And Reference. Routledge.

Islam, R., Islam, R. \& Mazumder, T. (2010). Mobile application and its global impact. International Journal of Engineering \& Technology (IJEST), 10(6), 72-78.

ITU-T TechWatch Alert (2009). Mobile Applications, 1-5.

Jolliffe, I. T. (1986). Principal component analysis. New York: Springer. 
Kaya, Y. Ç., Kaya, M. \& Yıldırım, S. Ö. (2014). Lokasyon tabanlı mobil kampüs uygulaması ve kullanılabilirlik değerlendirmesi. UYMS, 222-232.

Kushwaha, A. \& Kushwaha, V. (2011). Location based services using android mobile operating system. International Journal of Advances in Engineering \& Technology, 1(1), 14-20.

Lee, Y. E. \& Benbasat, I. (2004). A framework for the study of customer interface design for mobile commerce. International Journal of Electronic Commerce, 8(3), 79-102.

Litchfield, S. (2010). Defining the smartphone. Erişim tarihi: 29.10.2017, http://www.allaboutsymbian.com/features/item/Defining the_Smartphone.php.

MacCallum, R. C., Browne, M. W. \& Sugawara, H. M. (1996). Power analysis and determination of sample size for covariance structure modeling. Psychological methods, 1(2), 130-149.

Mobile App Usage - Statistics \& Facts, Erişim tarihi: 30.10.2017, https://www.statista.com/topics/1002/mobileapp-usage/

Öğrenim Düzeyine Göre Ö̆̆renci Sayısı, 2017-2018 Yükseköğretim Istatistikleri, Erişim tarihi: 04.11.2017, https://istatistik.yok.gov.tr/

Öz, B. K. (2014). Examining place attachment from a foursquare perspective (Doktora tezi). Middle East Technical University, Ankara.

Smartphones are more common in Europe, U.S., less so in developing countries, (2016), Erişim tarihi: 02.11.2017,_ http://www.pewresearch.org/fact-tank/2017/06/28/10-facts-about-smartphones/ft 17-0628_smartphone_map/

Staista, S. (2017). Smartphones - statistics \& facts. Erişim tarihi: 05.11.2017, https://www.statista.com/topics/840/smartphones 